\title{
Induction of interleukin-8 (CXCL-8) by tumor necrosis factor- $\alpha$ and leukemia inhibitory factor in pancreatic carcinoma cells: Impact of CXCL-8 as an autocrine growth factor
}

\author{
HIDENOBU KAMOHARA, MASASHI TAKAHASHI, TAKATOSHI ISHIKO, MICHIO OGAWA and HIDEO BABA
}

Department of Gastroenterological Surgery, Graduate School of Medical Sciences, Kumamoto University, 1-1-1 Honjo, Kumamoto 860-8556, Japan

Received December 18, 2006; Accepted February 14, 2007

\begin{abstract}
Pancreatic carcinoma is one of the most lethal of the gastrointestinal malignant tumors. Chronic inflammation leads to cancer development and progression. Interleukin-8 (CXCL-8) is a CXC chemokine, which plays an important role in neutrophil chemotaxis and activation. We previously reported that CXCL-8 was produced by a variety of human carcinoma cells and tissues, and that CXCL- 8 promoted proliferation in pancreatic carcinoma cells (SUIT-2). In the present study, we analyzed whether various cytokines affect cell proliferation by CXCL-8 expression in pancreas carcinoma cells. All examined pancreatic carcinoma cells expressed CXCL-8 and TNFRII mRNA constitutively in RPMI-1640 medium without FBS. TNF- $\alpha$, LIF, IL-1 1 , IL-6, IL- 8 , or IFN- $\beta$ enhanced the expression of CXCL-8 mRNA, but IL-10 did not in Hs-700T cells. Actinomycin D suppressed and cycloheximide augmented CXCL-8 mRNA which was induced by TNF- $\alpha$ or not. The half-life of CXCL- 8 mRNA was 36.5 min by $\mathrm{TNF}-\alpha$ and $35.2 \mathrm{~min}$ by no stimulation. In our previous study, LIF promoted cell growth in Hs-700T cells. LIF induced CXCL- 8 mRNA in a dose- and time-dependent manner. Addition of recombinant CXCL-8 did not induce cell growth of Hs-700T. Anti-CXCL-8 IgG significantly suppressed cell growth. CXCL-8 would act as an autocrine growth factor in Hs-700T cells, which expressed CXCL-8 mRNA highly without stimulation. Curcumin (diferuloylmethane), NF- $\mathrm{KB}$ inhibitor, suppressed cell proliferation in Hs-700T cells. These results suggest that CXCL-8 plays a pivotal role in progression of pancreatic cancer, and its expression is influenced by inflammatory cytokines in pancreatic tumor microenvironment.
\end{abstract}

Correspondence to: Dr Hidenobu Kamohara, Department of Gastroenterological Surgery, Graduate School of Medical Sciences, Kumamoto University, 1-1-1 Honjo, Kumamoto 860-8556, Japan E-mail:kamo.kamo@tkg.bbiq.jp

Key words: interleukin-8, inflammation, pancreatic cancer

\section{Introduction}

Pancreatic cancer is an aggressive disease in gastrointestinal malignancy. Surgical resections of tumor are only effective therapy before it has spread outside the pancreas, but have little effect with locally advanced or metastatic disease. Other current therapies, such as chemotherapy, radiation, and immunotherapy, rarely improve the prognosis of patients bearing pancreatic cancer, whereas they can alter the quality of life by controlling the symptoms and complications. Chronic inflammation, including hepatitis, gastritis, and colitis, causes cancer development by genetic alterations and cellular transformations (1). Chronic pancreatitis also increases the risk of developing pancreatic cancer $(2,3)$. Understanding the mechanisms underlying the interaction between chronic inflammation and cancer progression would provide novel insights for therapeutic intervention.

Interleukin-8 (CXCL-8) was initially isolated as neutrophil chemotactic factor by Yoshimura et al (4). CXCL-8 is a pleiotropic CXC chemokine, which plays an important role in neutrophil chemotaxis and activation. CXCL-8 is produced by a variety of cells, including leukocytes, endothelial cells, and fibroblasts. CXCL-8 contains the ELR (Glu-Leu-Arg) motif, which promotes angiogenesis by endothelial cell proliferation and MMP expression. The expression of CXCL-8 correlated with tumorgenesis and metastatic potentials in human carcinoma cells. CXCL-8 was expressed in obstructive pancreatitis by which pancreatic tumors can be caused. CXCL- 8 could be influenced by inflammatory cytokines in the tumor microenvironment.

We previously reported that CXCL- 8 was produced by a variety of human carcinoma cells (5) and tissues and promoted cell proliferation in pancreatic carcinoma cells (SUIT-2) $(6,7)$. In this study, we hypothesized that CXCL- 8 produced by pancreatic carcinoma cells increases proliferation in an autocrine manner. To test this hypothesis, expression of CXCL-8 mRNA was assessed for changes after the stimulation of cytokines, especially TNF- $\alpha$ and LIF. Pancreatic carcinoma cells were treated with recombinant CXCL- 8 or neutralizing antibody. We demonstrated that pancreatic carcinoma cells produced CXCL-8 in a cytokine network and CXCL-8 influenced cell growth in various conditions and mechanisms. 


\section{Materials and methods}

Reagents. Human recombinant tumor necrosis factor- $\alpha$ (TNF- $\alpha$ ), interleukin-1ß (IL-1ß), leukemia inhibitory factor (LIF), interleukin-6 (IL-6), interleukin-8 (CXCL-8) and interferon- $\beta$ (IFN- $\beta$ ) were purchased from R\&D systems (Minneapolis, MN). Anti-CXCL-8 polyclonal rabbit IgG and control rabbit IgG were from Santa Cruz Biotechnology (Santa Cruz, CA). 3-(4,5-dimethylthiazol-2-tl)-2,5-diphenyltetrazolium bromide (MTT), actinomycin D (Act D) and cycloheximide (CHX) were from Wako (Tokyo, Japan). Curcumin (diferuloylmethane) was from Sigma (St. Louis, MO). $\left[\alpha^{-32} \mathrm{P}\right] \mathrm{dCTP}$ was from ICN (Costa Mesa, CA). Human G3PDH cDNA were from Clontech (Palo Alto, CA). Phosphate-buffered saline (PBS), RPMI-1640, fetal bovine serum (FBS) and TRIzol reagent were from Life Technologies (Gaithersburg, MD).

Cell lines and cell culture. Carcinoma cell lines of the pancreas (BxPc-3, Hs-700T and Hs-766T, AsPc-1, PANC-1, Capan-1 and Capan-2) were purchased from the American Type Cell Culture (ATCC). SUIT-2 was maintained in our laboratory. All cell lines were cultured in RPMI-1640, supplemented with $10 \% \mathrm{FBS}$, penicillin (100 units $/ \mathrm{ml})$ and streptomycin $(100 \mathrm{mg} / \mathrm{ml})$ at $37^{\circ} \mathrm{C}$ in a humidified $5 \% \mathrm{CO}_{2}$ to $95 \%$ air atmosphere. The cells were starved overnight before isolation of mRNA.

Northern blot analysis. When carcinoma cells were harvested at $90 \%$ confluence, cells were washed with PBS. Cells were further incubated for $24 \mathrm{~h}$ in the serum-free medium until the experiment. Cells were stimulated with the reagents for indicated times. Total RNA of carcinoma cells was extracted by the guanidine thiocyanate-phenol-chloroform method as previously described (8). Northern blot analysis was performed as previously described (8). Membranes were hybridized with various ${ }^{32} \mathrm{P}$-labeled probes including CXCL-8 (kindly provided by Dr Teizo Yoshimura, NIH, NCI-Frederick, USA) for Northern blot analysis. G3PDH was purchased from Clontech. The results were expressed as a ratio to G3PDH.

RT-PCR analysis. RT-PCR analysis was performed as described previously (8). The following primers were used for PCR: TNFR II (Rp75) sense primer, 5'-GTGGAATG GACTACTCCAAGG-3'; TNFR II (Rp75) antisense primer, 5'-TCCTTCCCACCTTCATCTGT-3'; G3PDH sense primer, 5'-GAAATCCCATCACCATCTTCC-3'; G3PDH antisense primer, 5'-CCAGGGGTCTTACTCCTTGG-3'. The PCR fragments were analyzed by $1.5 \%$ agarose gel electrophoresis and visualized by ethidium bromide staining. PCR-assisted mRNA amplification was repeated twice for at least two separately prepared cDNA samples for each experiment. Data was representative in at least three different experiments.

Cell proliferation assay. Carcinoma cells were washed by PBS, and suspended at $1 \times 10^{5}$ cells $/ \mathrm{ml}$ in medium (RPMI$1640+2 \% \mathrm{FBS})$. Cells were transferred in triplicate to the 96well microtitre plates containing diluted recombinant human TNF- $\alpha$, LIF or CXCL-8. Plates were incubated for indicated periods. To evaluate the proliferation of pancreatic carcinoma cells, we performed MTT assay as described (9).

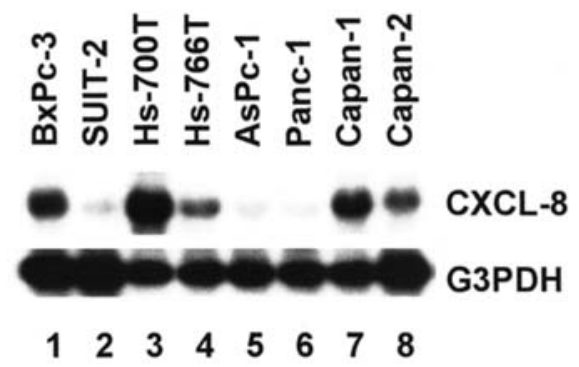

Figure 1. Pancreatic carcinoma cells constitutively expressed CXCL-8 mRNA. Carcinoma cells were cultured at $70-80 \%$ confluent in a $25-\mathrm{cm}^{2}$ flask. They were then incubated with serum-starved medium for $24 \mathrm{~h}$, and mRNA was isolated. Approximately $10 \mu \mathrm{g}$ per lane total cellular RNA was used for Northern blot analysis.

A

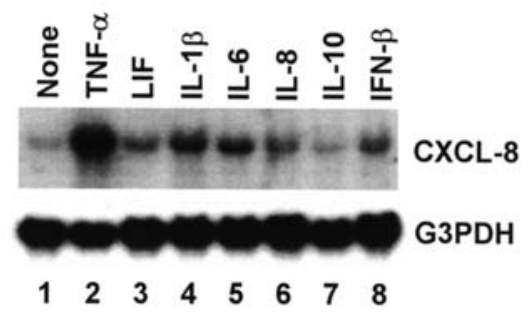

B

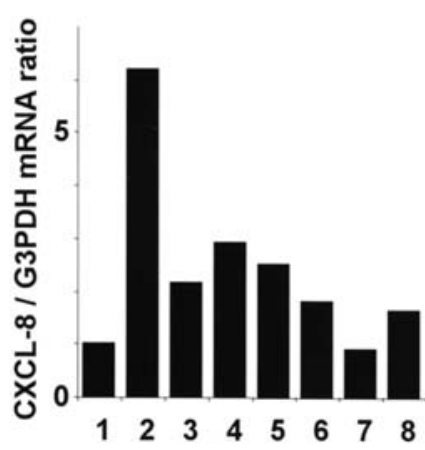

Figure 2. Regulation of CXCL-8 mRNA expression in Hs-700T cells. (A) Carcinoma cells were incubated in medium RPMI-1640 without FBS for $24 \mathrm{~h}$. Then, cells were incubated with or without TNF- $\alpha(10 \mathrm{ng} / \mathrm{ml}), \operatorname{LIF}(10 \mathrm{ng} / \mathrm{ml})$, IL-1ß (10 ng/ml), IL-6 (10 ng/ml), CXCL-8 (10 ng/ml), IL-10 (10 ng/ml) or IFN- $\beta(10 \mathrm{ng} / \mathrm{ml})$ for $8 \mathrm{~h}$. The expression of CXCL- 8 and G3PDH mRNA was analyzed by Northern blotting. Approximately $10 \mu \mathrm{g}$ per lane total cellular RNA was used. (B) Autoradiographic densities of each mRNA band were quantitated using a Bio-Image Analyzer (Fuji film Co., Tokyo, Japan). The results were standardized against the levels of G3PDH, and are presented as relative density. The level of expression detected in untreated cells equaled 1 .

Statistical analysis. The significance of differences in numerical data was evaluated using the $\chi^{2}$-test, or Student's t-test. The probability level of $\mathrm{p}<0.05$ was considered as the limit of significant difference.

\section{Results}

Expression of CXCL-8 mRNA in human pancreatic carcinoma cells. We firstly investigated whether pancreatic carcinoma cells can express CXCL-8 mRNA constitutively in RPMI-1640 medium without FBS. As shown in Fig. 1, CXCL-8 mRNA was detected in most pancreatic carcinoma cells by Northern 


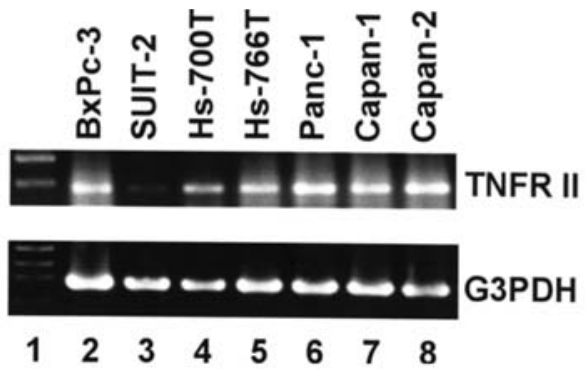

Figure 3. Pancreatic carcinoma cells expressed TNF receptor (TNFRII) mRNA. Carcinoma cells were cultured at $70-80 \%$ confluent in a $25-\mathrm{cm}^{2}$ flask. They were then incubated with serum-starved medium for $24 \mathrm{~h}$, and mRNA was isolated. Approximately $5 \mu \mathrm{g}$ per lane total cellular RNA was used for RT-PCR analysis.

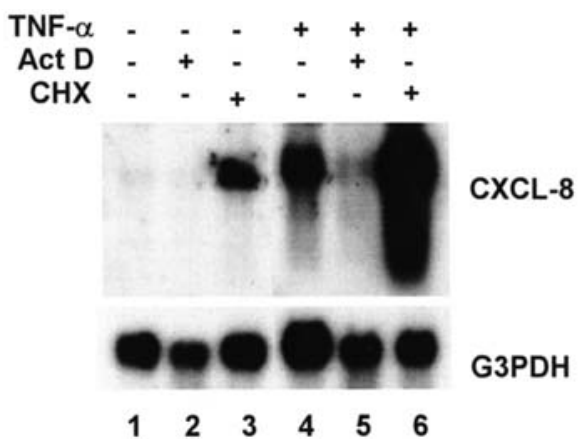

Figure 4. Effect of actinomycin D or cycloheximide on the expression of CXCL-8 mRNA by TNF- $\alpha$ in Hs-700T cells. Hs-700T cells were serumstarved and then treated with TNF- $\alpha(10 \mathrm{ng} / \mathrm{ml})$ in combination with actinomycin D $(4 \mu \mathrm{M})$, or cycloheximide $(50 \mu \mathrm{M})$. Total cellular RNA $(10 \mu \mathrm{g})$ was extracted and analyzed by Northern blotting.

blotting. Especially, Hs-700T expressed a large amount of CXCL-8 mRNA transcript (lane 3).

Regulation of CXCL-8 mRNA expression by various cytokines in $H s-700 T$ cells. We examined the effect of TNF- $\alpha$, IL-1ß, LIF, IL-6, CXCL-8, IL-10 or IFN- 3 on CXCL-8 mRNA expression in Hs-700T cells. In comparison with cells incubated in medium (Fig. 2A and B, lane 1), TNF- $\alpha$, IL-1B, LIF, IL-6, CXCL-8 or IFN- $\beta$ further augmented the expression levels of CXCL-8 mRNA in Hs-700T cells (Fig. 2A and B, lanes 2-6 and 8$)$. TNF- $\alpha$ was markedly upregulated to maximum effect (6.2-fold), whereas IL-10 was not significantly upregulated (0.9-fold) in Hs-700T cells (Fig. 2A and B, lane 7). Similarly, we observed upregulation of CXCL- 8 mRNA expression by these cytokines, especially TNF- $\alpha$ and IL-1ß, in other pancreas carcinoma cells, such as BxPc-3, SUIT-2, Hs-766T and Panc-1 cells (data not shown).

Expression of TNF receptor $m R N A$ in pancreas carcinoma cells. TNF- $\alpha$ binds two kinds of receptors, the 55-kDa, type I (TNFR I) and the 75-kDa, type II (TNFR II), which mediate gene expression through TNFR associated factor 2 (TRAF2) cooperatively. TNFRI induces apoptosis through TNFRassociated death domain (TRADD) protein (10). We analyzed the expression of TNFR II mRNA after serum-starvation in pancreatic carcinoma cells by RT-PCR analysis. As shown in
A

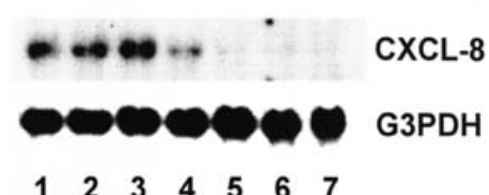

$\begin{array}{lllllll}1 & 2 & 3 & 4 & 5 & 6 & 7\end{array}$

B

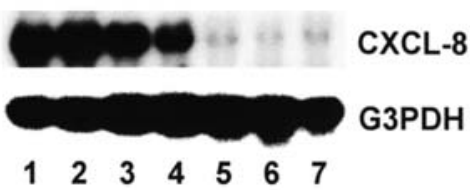

C

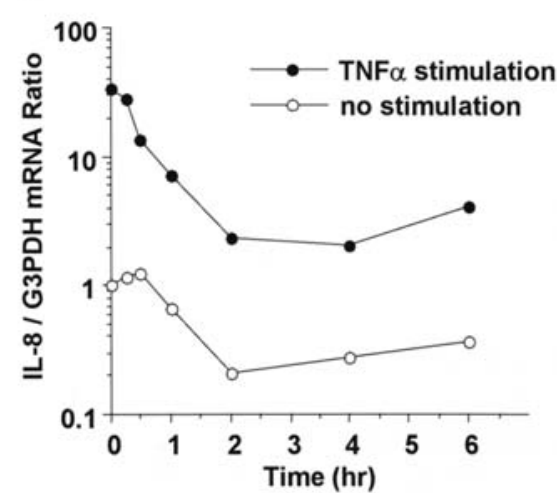

Figure 5. Stability of CXCL-8 mRNA transcript by TNF- $\alpha$ in Hs-700T cells Carcinoma cells were serum-starved and then treated with CXCL-8 $(10 \mathrm{ng} / \mathrm{ml})$ for $4 \mathrm{~h}$. Additionally, cells were incubated with actinomycin $\mathrm{D}(4 \mu \mathrm{M})$ for various lengths of time. Total cellular RNA $(10 \mu \mathrm{g})$ was extracted and analyzed by Northern blotting. (A) No treatment. (B) TNF- $\alpha$ treatment. (C) Autoradiographic densities of each mRNA band were quantitated using a Bio-Image Analyzer (Fuji film Co., Tokyo, Japan). The results were standardized against the levels of G3PDH, and are presented as relative density. The level of expression detected in untreated cells after the stimulation of actinomycin $\mathrm{D}$ for 15 min equaled 1 .

Fig. 3, the expression of TNFR II mRNA was detectable in most pancreatic carcinoma cells constitutively. These results indicated that TNF- $\alpha$ could induce CXCL- 8 expression through TNFR II in pancreatic carcinoma cells.

Effect of actinomycin $D$ or cycloheximide on the expression of CXCL-8 mRNA by TNF- $\alpha$ in Hs-700T cells. To investigate whether TNF- $\alpha$ induces de novo protein synthesis, we analyzed the effect of transcript synthesis inhibitor, actinomycin D (Act D), and protein synthesis inhibitor, cycloheximide (CHX), on the expression of CXCL-8 mRNA by Northern blotting. Cells were stimulated with Act D or CHX for $3 \mathrm{~h}$, and followed by the stimulation of TNF- $\alpha$ or not. As shown in Fig. 4, TNF- $\alpha$ enhanced CXCL-8 mRNA expression in comparison with untreated cells (lanes 1 and 4) and Act D markedly suppressed CXCL- 8 mRNA expression (lanes 2 and 5). CHX augmented CXCL-8 mRNA which was induced by TNF- $\alpha$ or not (lanes 3 and 6). The increase of CXCL-8 mRNA transcripts was dependent on de novo mRNA transcription and they did not require other protein synthesis. These results indicate that TNF- $\alpha$ promotes de novo synthesis of CXCL-8 in Hs-700T cells.

Effect of TNF- $\alpha$ on the stability of CXCL-8 transcripts in $H s-700 T$ cells. We next evaluated whether TNF- $\alpha$ affects the 
A

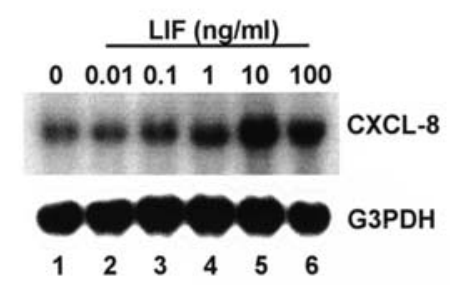

B

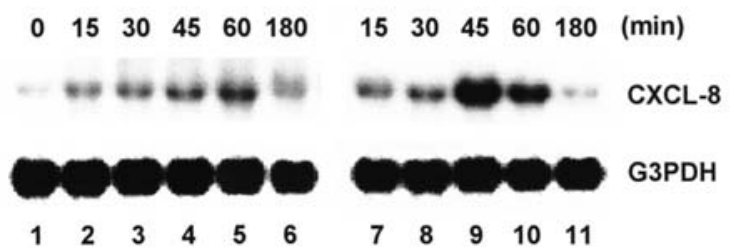

C

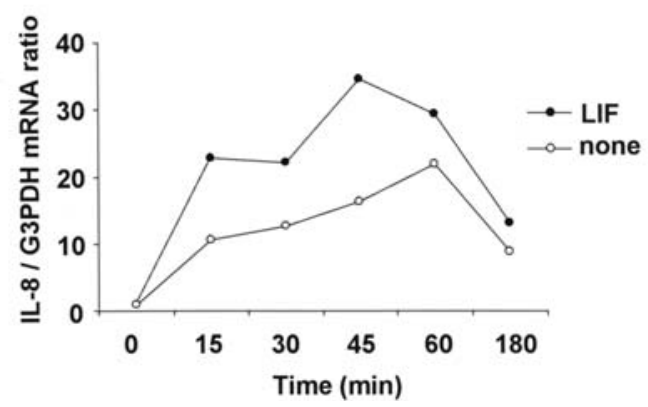

Figure 6. Regulation of CXCL-8 mRNA expression by LIF in Hs-700T cells. Carcinoma cells were serum-starved and then treated with indicated concentrations of human recombinant LIF for $8 \mathrm{~h}$. Total cellular RNA was extracted and the expression of CXCL-8 mRNA was analyzed by Northern blotting. (A) CXCL-8 mRNA induction by dosage of LIF, 0-100 ng/ml. (B) Kinetics of CXCL-8 mRNA induction by $10 \mathrm{ng} / \mathrm{ml}$ concentration of LIF. (C) Autoradiographic densities of each mRNA band were quantitated using a Bio-Image Analyzer (Fuji film Co., Tokyo, Japan) in kinetics study. The results were standardized against the levels of G3PDH, and are presented as relative density. The level of expression detected in untreated cells equaled 1.

stability of CXCL-8 mRNA post-transcriptionally in Hs-700T cells. Cells were incubated in medium with or without TNF- $\alpha$ for $3 \mathrm{~h}$, and followed by addition of Act D for the indicated time. The half-life of CXCL- 8 mRNA was 36.5 min by TNF- $\alpha$ and 35.2 min by no stimulation (Fig. 5). TNF- $\alpha$ did not affect CXCL-8 mRNA stabilization in comparison with control, indicating that TNF- $\alpha$ did not contribute to protection from CXCL-8 mRNA degradation after transcription.

Regulation of CXCL-8 mRNA expression by LIF in Hs-700T cells. Previously we reported that Hs-700T cells promoted cell growth by the stimulation of LIF. We clarified the underlying mechanism of induction of LIF, $c$-fos, junB, and cyclinE mRNA (8). CHX suppressed endogenous LIF mRNA expression after the stimulation of TNF $\alpha$ or LIF (data not shown). This led us to assume that induction of LIF requires de novo other protein synthesis. We evaluated whether LIF induces the expression of CXCL- 8 mRNA by Northern blotting in Hs-700T cells. Cells were serum-starved and then stimulated with various LIF concentrations. As shown in Fig. 6A, addition of LIF induced endogenous CXCL-8 mRNA expression in a dose-dependent fashion, especially $>0.1 \mathrm{ng} / \mathrm{ml}$ concentration of LIF (lanes 3-6). Additive LIF
A

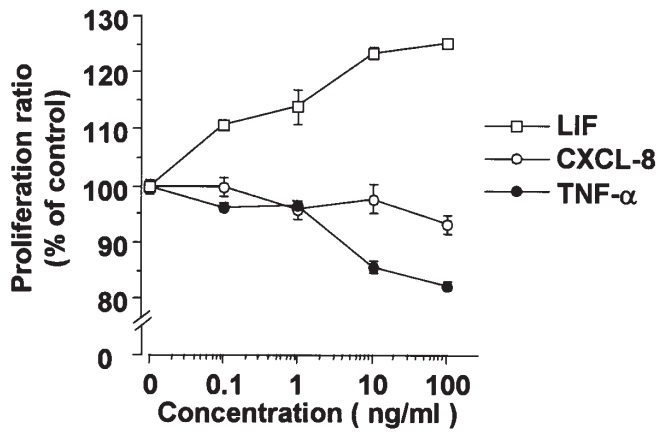

B

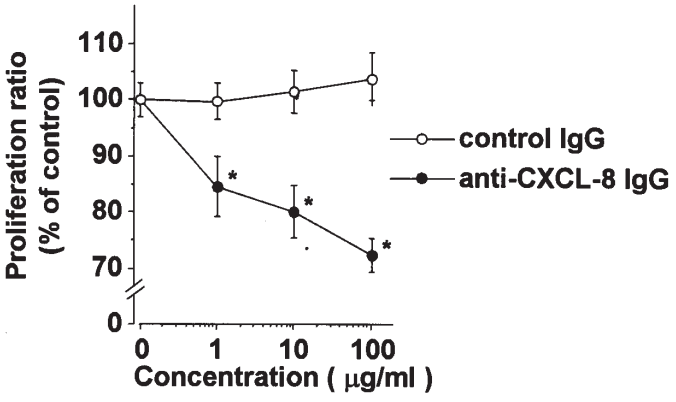

C

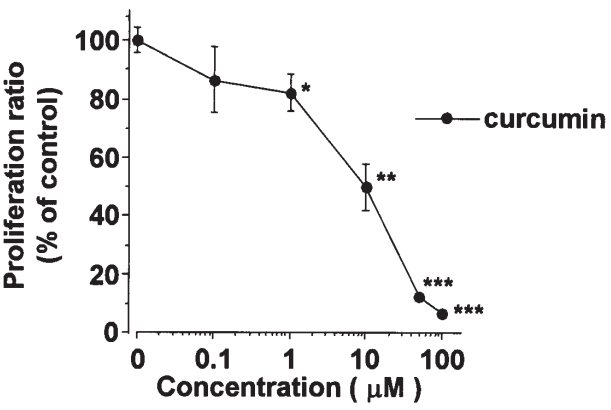

Figure 7. Effect of CXCL-8, TNF- $\alpha$, LIF, anti-CXCL-8 IgG, or curcumin on cell proliferation of Hs-700T cells. Carcinoma cells $\left(1 \times 10^{5}\right.$ cells $\left./ \mathrm{ml}\right)$ were exposed to various concentrations of CXCL- 8 , TNF- $\alpha$, LIF or anti-CXCL-8 IgG $(0-100 \mathrm{ng} / \mathrm{ml})$ in triplicate using the 96 -well microtitre plates for $48 \mathrm{~h}$. Then, MTT assay was performed as described in Materials and methods. Data were shown as mean $\pm \mathrm{SD}$ of three-four wells. Statistical significance was evaluated by the Mann-Whitney t-test. (A) Effect of CXCL-8, TNF- $\alpha$ or LIF. (B) Effect of anti-CXCL-8 IgG or control IgG. * $\mathrm{P}<0.001$. (C) Effect of curcumin. ${ }^{*} \mathrm{P}=0.0162,{ }^{* *} \mathrm{P}=0.0007,{ }^{* * *} \mathrm{P}<0.0001$.

also induced the expression of CXCL- 8 mRNA in the early phase of kinetics and maximally after stimulation for $45 \mathrm{~min}$ (Fig. 6B and C).

Suppression of cell growth by neutralizing anti-CXCL-8 IgG or curcumin in Hs-700T cells. The promotion of cell growth might depend on CXCL-8 expression in Hs-700T cells. To clarify this hypothesis, we examined whether the stimulation of CXCL-8 promotes cell growth in Hs-700T cells. We firstly investigated the effect of recombinant CXCL-8, TNF- $\alpha$ and LIF on cell proliferation by MTT assay. As shown in Fig. 7A, LIF promoted cell growth in a dose-dependent manner, however CXCL-8 did not have a significant effect after incubation for $48 \mathrm{~h}$. TNF- $\alpha$ suppressed cell growth at a dose of $10-100 \mathrm{ng} / \mathrm{ml}$ and cellular morphology of treated cells partially exhibited loss of volume, rounding shape and chromatin condensation, all being morphological features of cells in apoptosis. As Hs-700T expressed both CXCL-8 
(Fig. 1) and its receptor mRNA (data not shown) constitutively, CXCL-8 might function as an autocrine growth factor. AntiCXCL-8 IgG suppressed cell growth with increasing dose and its inhibitory effects were significant with $1-100 \mu \mathrm{g} / \mathrm{ml}$ of anti-CXCL-8 IgG (Fig. 7B). The promoter of CXCL-8 consists of consensus sequence motif of NF- $\mathrm{NB}$, which is strongly activated by TNF- $\alpha$. Curcumin is a strong inhibitor of NF- $\mathrm{BB}$ activation. We examined the effect of curcumin on growth of Hs-700T cells by MTT assay. Carcinoma cells were incubated in RPMI-1640 medium with curcumin or not for 48 h. As shown in Fig. 7C, curcumin inhibited cell growth in a dose-dependent manner and a high dose of curcumin, $>50 \mu \mathrm{M}$, blocked it completely. These results suggested that constitutive expression of a high concentration of CXCL-8 played a major biological role and an optimal dose of CXCL-8 could affect cell growth effectively in Hs-700T cells.

\section{Discussion}

In our previous study, CXCL-8 was produced constitutively and commonly in a variety of human carcinoma cells derived from lung, stomach, pancreas, esophagus, colon, gall bladder, breast, and melanoma (5). High amounts of CXCL-8 expression have been reported in various human malignancies, including leukocytes, melanocytes, mesothelium, brain, ovary, prostate, kidney, neck, breast, colon, and stomach (11). Thus, CXCL-8 was produced at high incidence and amount in most carcinoma cells. All examined pancreatic carcinoma cell lines produced CXCL-8 (12). This is consistent with our results.

Clinically, pancreatic cancer is a disease with the worst prognosis, which can metastasize to the liver and invade surrounding tissues easily. Serum concentration of IL-6, CXCL-8, IL-10, and IL-1RA were elevated in patients who had pancreatic cancer in comparison with healthy individuals. Serum concentration of CXCL- 8 correlated with weight loss, but not with survival (13). Thus, CXCL-8 could be an important molecule in pancreatic cancer bearing patients. Metabolic imbalance between vascularization and tumor formation in aggressive pancreatic cancer could lead to low blood flow and low extracellular $\mathrm{pH}$ in tumor microenvironment. Hypoxia and acidosis enhanced expression of CXCL-8 by activation of NF- $\mathrm{\kappa B}$ and AP-1 in pancreatic cancer cells (14).

In the present study, we demonstrated that inflammatory cytokines, especially TNF- $\alpha$ and LIF, induced CXCL-8 expression in pancreatic carcinoma cells. Act D did not affect post-transcriptionally the half life of CXCL- 8 mRNA after the stimulation of TNF- $\alpha$. TNF- $\alpha$ upregulated CXCL- 8 drastically in de novo pathway. In contrast, IL-1ß induces stabilization of CXCL-8 mRNA in malignant breast cancer cells via the $3^{\prime}$ untranslated region: involvement of divergent RNA-binding factors HuR, KSRP and TIAR (15). Nitric oxide also upregulated the expression of CXCL- 8 by an increase in CXCL-8 gene transcription and mRNA stability in pancreatic cancer (16). LIF induced CXCL-8 mRNA in a dose- and time-dependent manner in Hs-700T cells. LIF expression correlated with CXCL-8 expression in psoriasis, but not skin cancers $(17,18)$.

Previous studies have revealed that CXCL- 8 contributes to cancer progression, such as proliferation, metastasis, and angiogenesis (19) in a variety of tumor microenvironments. We also demonstrated that neutralizing anti-CXCL-8 IgG suppressed cell growth in Hs-700T which produced a high amount of CXCL-8 in the culture supernatants. This growth promoting activity is consistent with other pancreatic carcinoma cells, including SUIT-2 and Capan-1 cells. CXCL-8, produced by carcinoma cells, acts as an autocrine growth factor in pancreatic carcinoma cells. However, addition of CXCL-8 failed to promote cell growth. An optimal dose of CXCL-8 has a growth activity function, but excess doses do not. Receptors of CXCL-8, CXCR-1 and CXCR-2, might be insufficient to express and supply after receptor internalization in Hs-700T cells. Although TNF- $\alpha$ induced CXCL-8 mRNA expression strongly in de novo synthesis pathway, TNF- $\alpha$ suppressed cell proliferation in any tested dose, $0.1-100 \mathrm{ng} / \mathrm{ml}$, in Hs-700T cells. Apoptotic activity of TNF- $\alpha$ is dominant via receptor containing death domain, particularly $55-\mathrm{kDa}$ TNF receptor (TNFRI), despite the strong inducer of CXCL-8. Our previous reports demonstrated that exogenous LIF promoted cell growth by the mechanisms upregulating endogenous LIF and LIFR expression in Hs-700T cells which produced a small amount of $\operatorname{LIF}(8,20)$. In this study, LIF induced expression of CXCL- 8 transcript at levels that were limited in comparison with TNF- $\alpha$. Thus, our data suggest that CXCL-8 functions as an autocrine growth factor which facilitates pancreatic cancer progression, and its expression is influenced by inflammatory cytokines, such as TNF- $\alpha$ and LIF. CXCL-8 also could act as a paracrine and endocrine factor, and affect the interaction with stromal tissues, including fibroblasts, endothelial cells, and infiltrative leukocytes in pancreatic tumor microenvironments.

Curcumin is a food element which has inhibitory activity of $N F-\kappa B$. We examined previously that curcumin-downregulated NF- $\mathrm{NB}$ activation correlated with $\mathrm{CXCL}-8$ production and suppressed cell growth significantly in pancreatic

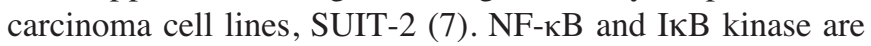
constitutively active in human pancreatic cells, and their downregulation by curcumin is associated with the suppression of proliferation and the induction of apoptosis (21). In the present study, curcumin also suppressed cell proliferation in Hs-700T cells. It could be beneficial to use an NF- $\mathrm{\kappa B}$ inhibitor, such as curcumin, to treat pancreatic cancer with high CXCL-8 production.

These results suggest that CXCL- 8 could be a molecular target to develop new strategies for clinical anti-cancer therapy and diagnosis in pancreatic cancer.

\section{Acknowledgements}

Authors thank Dr K. Sakamoto, H. Egami and S. Mita for their criticism and invaluable discussions throughout this study.

\section{References}

1. De Visser KE, Eichten A and Coussens LM: Paradoxical roles of the immune system during cancer development. Nature Rev Cancer 6: 24-37, 2006.

2. Lowenfels AB, Maisonneuve P, Cavallini G, Ammann RW, Lankisch PG, Andersen JR, Dimagno EP, Andren-Sandberg A and Domellof L: Pancreatitis and the risk of pancreatic cancer. International Pancreatitis Study Group. New Eng J Med 328: 1433-1437, 1993. 
3. Malka P, Hammel P, Maire F, Rufat P, Maderia I, Pessione F, Levy P and Ruszniewski P: Risk of pancreatic adenocarcinoma in chronic pancreatitis. Gut 51: 849-852, 2002

4. Yoshimura T, Matsushima K, Oppenheim JJ and Leonard EJ: Neutrophil chemotactic factor produced by lip polysaccharide (LPS)-stimulated human blood mononuclear leukocytes: partial characterization and separation from interleukin 1 (IL 1). J Immunol 139: 788-793, 1987.

5. Sakamoto K, Masuda T, Mita S, Ishiko T, Nakashima Y, Arakawa H, Egami H, Harada S, Matsushima K and Ogawa M: Interleukin- 8 is constitutively and commonly produced by various human carcinoma cell lines. Int J Clin Lab Res 22: 216-219, 1992.

6. Ishiko T, Sakamoto K, Yamashita Y, Masuda H, Kamohara H, Mita S, Hirashima $\mathrm{M}$ and Ogawa M: Carcinoma cells express IL- 8 and IL- 8 receptor: their inhibition attenuates the growth of carcinoma cells. Int J Oncol 5: 119-122, 1995.

7. Hidaka H, Ishiko T, Furuhashi T, Kamohara H, Suzuki S, Miyazaki M, Ikeda O, Mita S, Setoguchi T and Ogawa M: Curcumin inhibits interleukin 8 production and enhances interleukin 8 receptor expression on the cell surface: impact on human pancreatic carcinoma cell growth by autocrine regulation. Cancer 95: 1206-1214, 2002.

8. Kamohara H, Sakamoto K, Ishiko T, Masuda Y, Abe T and Ogawa M: Leukemia inhibitory factor induces apoptosis and proliferation of human carcinoma cells through different oncogene pathways. Int J Cancer 72: 687-695, 1997.

9. Kamohara H, Sakamoto K, Ishiko T, Mita S, Masuda Y, Abe T and Ogawa M: Human carcinoma cell lines produce biologically active leukemia inhibitory factor (LIF). Res Commun Mol Pathol Pharmacol 85: 131-140, 1994.

10. Aggarwal BB: Signaling pathways of the TNF superfamily: a double-edged sword. Nat Rev Immunol 3: 745-756, 2003.

11. Xie K: Interleukin-8 and human cancer biology. Cytokine Growth Factor Rev 12: 375-391, 2001.

12. Wigmore SJ, Fearon KC, Sangster K, Maingay JP, Garden OJ and Ross JA: Cytokine regulation of constitutive production of interleukin- 8 and -6 by human pancreatic cancer cell lines and serum cytokine concentrations in patients with pancreatic cancer. Int J Oncol 21: 881-886, 2002.
13. Ebrahimi B, Tucker SL, Li D, Abbruzzese JL and Kurzrock R: Cytokines in pancreatic carcinoma: correlation with phenotypic characteristics and prognosis. Cancer 101: 2727-2736, 2004.

14. Shi Q, Le X, Wang B, Xiong Q, Abbruzzese JL and Xie K: Regulation of interleukin-8 expression by cellular $\mathrm{pH}$ in human pancreatic adenocarcinoma cells. J Interferon Cytokine Res 20: 1023-1028, 2000.

15. Suswam EA, Nabors LB, Huang Y, Yang X and King PH: IL-1beta induces stabilization of IL- 8 mRNA in malignant breast cancer cells via the 3' untranslated region: involvement of divergent RNA-binding factors HuR, KSRP and TIAR. Int J Cancer 113: 911-919, 2005.

16. Xiong Q, Shi Q, Le X, Wang B and Xie K: Regulation of interleukin-8 expression by nitric oxide in human pancreatic adenocarcinoma. J Interferon Cytokine Res 21: 529-537, 2001.

17. Szepietowski J, Walker C, Hunter JA and McKenzie RC: Elevated leukaemia inhibitory factor (LIF) expression in lesional psoriatic skin: correlation with interleukin (IL)-8 expression. J Dermatol 28: 115-122, 2001.

18. Szepietowski JC, Walker C, McKenna DB, Hunter JA and McKenzie RC: Leukaemia inhibitory factor and interleukin-8 expression in non-melanoma skin cancers. Clin Exp Dermatol 26: 72-78, 2001

19. Koch AE, Polverini PJ, Kunkel SL, Harlow LA, Di Pietro LA, Elner VM, Elner SG and Strieter RM: Interleukin-8 as a macrophage-derived mediator of angiogenesis. Science 258: 1798-1801, 1992.

20. Kamohara H, Ogawa M, Ishiko T, Sakamoto K and Baba H: Leukemia inhibitory factor functions as a growth factor in pancreas carcinoma cells: Involvement of regulation of LIF and its receptor expression. Int J Oncol 30: 977-983, 2007.

21. Li L, Aggarwal BB, Shishodia S, Abbruzzese J and Kurzrock R: Nuclear factor-kappaB and IkappaB kinase are constitutively active in human pancreatic cells, and their down-regulation by curcumin (diferuloylmethane) is associated with the suppression of proliferation and the induction of apoptosis. Cancer 101: 2351-2362, 2004. 